\title{
Ductal carcinoma in situ of the breast, a population-based study of epidemiology and pathology
}

\author{
A Kricker", , C Goumas' and B Armstrong ${ }^{2}$ \\ 'School of Public Health, Level 6, Medical Foundation Building K25, University of Sydney NSW 2006, Australia; ${ }^{2}$ School of Public Health, Edward Ford \\ Building A27, University of Sydney NSW 2006, Australia
}

In a population-based series of 2109 women with ductal carcinoma in situ (DCIS) diagnosed in 1995-2000 in New South Wales, Australia, incidence increased by an average of 5.5\% a year, mostly between 1995 and 1996 and in women 50-69 years of age. This increase paralleled the increases in mammographic screening. BreastScreen NSW, an organised mammographic screening programme, detected $65 \%$ of all DCIS. High-grade lesions were $54 \%$ of all lesions and were more likely to be $2+\mathrm{cm}$ in diameter $(\mathrm{OR}=2.12,95 \% \mathrm{Cl} 1.46-3.14)$ than low-grade lesions. In all, $40 \%$ of DCIS in women younger than 40 years was $2+\mathrm{cm}$ in diameter compared with $21 \%$ in women 40 years and older. Young age, high grade, mixed architecture and multifocality were significant and independent predictors of $2+\mathrm{cm}$ DCIS.

British Journal of Cancer (2004) 90, 1382-1385. doi: I0.1038/sj.bjc.660I677 www.bjcancer.com

Published online 24 February 2004

(c) 2004 Cancer Research UK

Keywords: DCIS; epidemiology; pathology; population-based

The epidemiology of ductal carcinoma in situ (DCIS) has yet to be described adequately. While mammographic screening has undoubtedly caused increasing diagnosis of DCIS (Ernster et al, 1996, 2002; Levi et al, 1997; Barchielli et al, 1999), studies to date have mainly been small (Levi et al, 1997; Barchielli et al, 1999) or described populations that had no organised screening programme (Choi et al, 1996; Ernster et al, 1996; Zheng et al, 1997). Population-based descriptions of epidemiology and pathology of DCIS in sizeable screened populations are nonexistent.

We describe the epidemiology and pathology of newly diagnosed DCIS in the 2.7 million female population of New South Wales (NSW) Australia in 1995-2000.

\section{MATERIALS AND METHODS}

\section{Data}

NSW women with a first diagnosis of DCIS in 1995-2000 and notified to the NSW Central Cancer Registry were eligible for the study; those with a previous or simultaneous (same month) diagnosis of invasive breast cancer were excluded. Ductal carcinoma in situ has been notifiable in NSW since 1993, and by 1997 all but $4 \%$ of DCIS cases diagnosed by pathology laboratories were notified to the Cancer Registry (unpublished data).

Two experienced Cancer Registry personnel extracted information on the type of specimen, size, grade, architecture, presence or absence of necrosis and multifocality of DCIS, and clearance and width of the margins from pathology reports (Kricker et al, 1999).

The frequency of mammography was obtained from reports of an organised screening programme, BreastScreen NSW (Estoesta

*Correspondence: Dr A Kricker; E-mail: annek@health.usyd.edu.au Received 17 September 2003; revised 15 December 2003; accepted 7 January 2004; published online 24 February 2004 et al, 2000; Productivity Commission, 2002), which began in 1991 and reached a steady state between 1995 and 2000. The numbers of bilateral mammograms reimbursed by the national health insurance scheme, Medicare, were also available for 1995-99 (http://www.hic.gov.au/providers/health_statistics/statistical_reporting/medicare.htm). These mammograms would include an unknown but not high proportion of mammograms that were primarily diagnostic. BreastScreen and Medicare account for most of the screening mammography in Australia.

\section{Analyses}

Incidence rates and 95\% confidence intervals (CIs) (Dobson et al, 1991) were calculated in 5- (DCIS) or 10-year (mammography) age groups and age-standardised to the World population. The annual percentage changes in rates were estimated in negative binomial models with terms for age group and year of diagnosis.

Cases were allocated to urban or rural areas using BreastScreen's classification (Estoesta et al, 2000) and to five socioeconomic (SES) groups (Australian Bureau of Statistics, 1998), and variation among them tested in Poisson regression models.

The heterogeneity of DCIS distributions by size and grade among age groups and type of architecture among years of diagnosis was evaluated by standard $\chi^{2}$ tests. Age, grade, architecture, multifocality and presence of necrosis were examined as predictors of size $(<2 \mathrm{~cm}, 2+\mathrm{cm})$ in logistic regression models that included year of diagnosis; the additional effects of urban or rural residence and SES of the women were also examined.

\section{RESULTS}

\section{Incidence}

In 1995-2000, 2109 NSW women were notified with DCIS. More than half (54\%) were 50-69 years of age, the target age group for 
breast cancer screening in NSW, and had the highest incidence (32.3 per 100000$)$ (Table 1 ).

Incidence at all ages increased from 1995 (6.8 per 100000$)$ to 2000 (8.9 per 100000) (annual average 5.5\%, 95\% CI 2.5-8.6), mostly between 1996 and 1997 (39\% increase) and in women 50 69 years of age (48\% increase 1996-1997) (Figure 1). Ductal carcinoma in situ rates were higher in 1998-2000 than 1995-1997 in every age group, but did not continue to increase except, perhaps, in women $70+$ years of age.

The incidence of DCIS was about $25 \%$ higher in urban than rural areas of NSW $(P<0.001)$ and increased strongly with increasing socio-economic status in Sydney $(P<0.001$, Table 1), but not other

Table I Incidence of ductal carcinoma in situ of the breast in NSW women in 1995-2000 by age, urban or rural residence and socioeconomic status

\begin{tabular}{|c|c|c|c|}
\hline & Number & Rate $^{\mathbf{a}}$ & $95 \% \mathrm{Cl}$ \\
\hline All NSW women & 2109 & 8.6 & $8.2-9.0$ \\
\hline \multicolumn{4}{|l|}{ Age group } \\
\hline $20-39$ & 91 & 1.4 & $1.1-1.7$ \\
\hline $40-49$ & 458 & 17.3 & $15.7-19.0$ \\
\hline $50-59$ & 634 & 31.8 & $29.4-34.4$ \\
\hline $60-69$ & 495 & 32.8 & $29.9-35.8$ \\
\hline $70-79$ & 354 & 28.8 & $25.8-32.0$ \\
\hline $80+$ & 77 & 10.6 & $8.4-13.3$ \\
\hline $50-69$ & 1129 & 32.2 & $30.4-34.2$ \\
\hline $70+$ & 431 & 24.2 & $21.9-26.7$ \\
\hline \multicolumn{4}{|l|}{ Urban \& rural area } \\
\hline All areas & 2100 & 8.5 & $8.2-8.9$ \\
\hline Urban & 1712 & 9.0 & $8.6-9.4$ \\
\hline Rural & 388 & 7.1 & $\begin{array}{c}6.3-7.8 \\
P<\left.0.00\right|^{b}\end{array}$ \\
\hline \multicolumn{4}{|c|}{ Socioeconomic status (Sydney Statistical Division only) } \\
\hline All areas & 1369 & 9.2 & $8.7-9.7$ \\
\hline I lowest & 205 & 7.2 & $6.2-8.2$ \\
\hline 2 & 197 & 7.5 & $6.4-8.6$ \\
\hline 3 & 226 & 8.5 & $7.4-9.8$ \\
\hline 4 & 342 & 10.9 & $9.7-12.1$ \\
\hline 5 highest & 399 & 11.2 & $\begin{array}{l}\mid 0.1-12.4 \\
P<\left.0.00\right|^{c}\end{array}$ \\
\hline
\end{tabular}

${ }^{a}$ Rates are per 100000 women age-standardised to the World population. ${ }^{b} \chi^{2}$ test for difference in rates between urban and rural (metro vs non-metro) - Poisson regression model. ${ }^{c} P$-value for heterogeneity and trend $<0.001$. areas of the State $(P=0.09)$. BreastScreen NSW detected $65 \%$ of incident DCIS, with higher proportions in women older than 50 years.

\section{Screening}

BreastScreen and Medicare screened 265.1 per 1000 women 40 years of age and older in 1995 and 284.6 in 1999; all the increase was in BreastScreen. BreastScreen screened twice as many women $50-69$ years of age (269.2 per 1000) as women $40-49(122.4)$ and $70+$ years (120.1) (Figure 2); Medicare screening rates in the two younger age groups were nearly equal. There was little difference in the screening rates between urban (189.0 per 1000) and rural (186.6) areas.

The numbers of DCIS detected were strongly correlated with the numbers of women screened by BreastScreen in 1995-2000 $(R=0.83, P<0.001)$. There was a weaker correlation between Medicare reimbursed mammograms and DCIS not detected by BreastScreen in 1995-1999 $(R=0.64, P=0.002)$.

\section{Pathology information}

Pathology reports were available for all but two cases of DCIS, mainly from excision or re-excision specimens (73\%) and mastectomies $(24 \%)$. Size was reported in $76 \%$, grade in $89 \%$ (both in 69\%), presence or absence of necrosis in 63\%, architecture

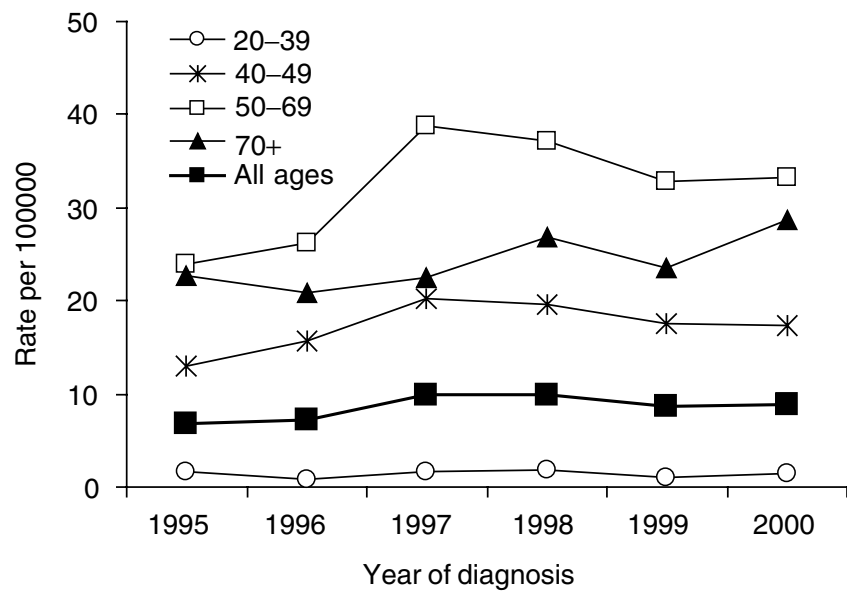

Figure I Trends in incidence of DCIS by age group in NSW women from 1995 to 2000. Rates were standardised by 5-year age intervals within broad age groups, using the World standard population.
Medicare-reimbursed mammograms in $1995-1999$

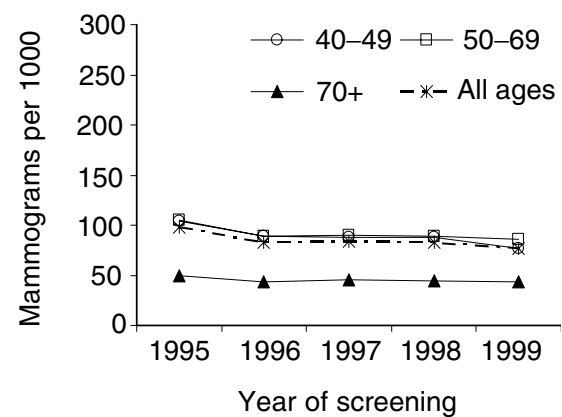

Figure 2 Mammogram rates in NSW women by age group - age-standardised in 10-year age groups to the World population. 
in $82 \%$ and clearance of the margins in $80 \% ; 37 \%$ had all these items. The width of margins was reported in only $41 \%$. All these items except the width of margins were appreciably more complete in 1998-2000 than in 1995-97.

More than half (54\%) the DCIS diagnosed in 1995-2000 were high grade and $39 \%$ were $2 \mathrm{~cm}$ or larger (Table 2). More DCIS were high grade at 20-39 and 50-69 years (57\%) than at other ages $(50 \%)(P=0.02)$ and a higher proportion were $2+\mathrm{cm}$ at $20-39$ $(53 \%)$ than 40 years and older $(38 \%)(P=0.01)$. Size, however, was not stated for more DCIS at 20-39 years (34\%) than other ages (24\%).

Most (65\%) of the DCIS were described as cribriform or solid, or a mixture in which these two types predominated. Fewer were identified as comedocarcinoma (10\%) in 1998-2000 than in 1995$1997(26 \%)$ and more as a mixture of types (45\% compared with $23 \%$; $P$ for difference between the two periods $<0.001)$. Highgrade DCIS were distributed across all types (mixed $32 \%$, comedocarcinoma $27 \%$, other specific types $21 \%$, no specific type $20 \%)$. Most of the $2+\mathrm{cm}$ DCIS were mixed $(45 \%)$ or other specific types $(27 \%)$ and few were comedocarcinoma (18\%) or no specific type $(9 \%)$.

Age, grade, architecture and multifocality were significant independent predictors of DCIS $2+\mathrm{cm}$ in size in a logistic regression model (Table 3 ). Two-fold higher odds of having $2+\mathrm{cm}$ DCIS appeared to lie with a young age (20-39 years), with high grade and with multifocal lesions. The excess risks of $2+\mathrm{cm}$ DCIS also lay with mixed types of architecture (OR 1.5) compared to comedocarcinoma and diagnosis in 1996 (OR 1.7), while a report that did not mention necrosis was associated with lower odds (OR 0.7) of a larger DCIS. Otherwise, there was no evident trend across these variables. Neither place of residence (urban or rural) nor SES was significantly predictive of $2+\mathrm{cm}$ DCIS or appreciably affected the above odds ratios when added to the model.

\section{DISCUSSION}

The main strengths of this study are its population base, detail and recency. Population-based registration of DCIS in NSW began 2 years before the first year of our study, and the study's first year coincided with that of complete population coverage by BreastScreen. Its main weakness is lack of linkage between the data sources (BreastScreen, Medicare and the Cancer Registry), without which we cannot fully describe the contribution of screening to the occurrence and outcomes of DCIS.

Table 2 Number, percent and rate of DCIS by grade and size in NSW in 1995-2000

\begin{tabular}{lcccc}
\hline & Number & $\%$ & Rate $^{\mathbf{a}}$ & $\mathbf{9 5 \%} \mathbf{~ C l}$ \\
\hline Grade & & & & \\
$\quad$ Low & 313 & 16.7 & 1.2 & $(1.1-1.4)$ \\
Intermediate & 542 & 29.0 & 2.2 & $(2.0-2.4)$ \\
High & 1015 & 54.3 & 4.2 & $(3.9-4.5)$ \\
Total & 1870 & 100.0 & 8.6 & $(8.2-9.0)$ \\
Unknown & 239 & & 0.9 & $(0.8-1.1)$ \\
Size & & & & \\
$0-0.9 \mathrm{~cm}$ & 505 & 31.5 & 2.1 & $(1.9-2.3)$ \\
I-1.9cm & 480 & 30.0 & 2.0 & $(1.8-2.2)$ \\
$2-2.9 \mathrm{~cm}$ & 278 & 17.4 & 1.1 & $(1.0-1.3)$ \\
$3+\mathrm{cm}$ & 339 & 21.2 & 1.4 & $(1.2-1.5)$ \\
Total & 1602 & 100.0 & 8.6 & $(8.2-9.0)$ \\
Unknown & 507 & & 2.0 & $(1.9-2.2)$ \\
\hline
\end{tabular}

${ }^{a}$ Rates are per 100000 women age-standardised to the World population.
Table 3 Association of $2+\mathrm{cm}$ DCIS with year of diagnosis, age, size, grade, necrosis and multifocality in NSW women in 1995-2000

\begin{tabular}{|c|c|c|c|c|c|}
\hline & $<2 \mathrm{~cm}$ & $2+\mathrm{cm}$ & OR & $(95 \% \mathrm{Cl})$ & $P$-value \\
\hline \multicolumn{6}{|l|}{ Year of diagnosis } \\
\hline 1995 & 112 & 46 & 1 & & \\
\hline 1996 & 120 & 89 & 1.66 & $(1.05-2.64)$ & \\
\hline 1997 & 190 & 106 & 1.19 & $(0.76-1.86)$ & \\
\hline 1998 & 209 & 105 & 0.74 & $(0.47-1.18)$ & \\
\hline 1999 & 159 & 129 & 1.25 & $(0.78-1.98)$ & \\
\hline 2000 & 184 & 135 & 1.05 & $(0.66-1.67)$ & 0.002 \\
\hline \multicolumn{6}{|l|}{ Age group } \\
\hline $20-39$ & 28 & 32 & 1.87 & $(1.07-3.27)$ & \\
\hline $40-49$ & 210 & 132 & 1.07 & $(0.82-1.40)$ & \\
\hline $50-69$ & 556 & 316 & I & & \\
\hline $70+$ & 180 & 130 & 1.39 & $(1.05-1.84)$ & 0.03 \\
\hline \multicolumn{6}{|l|}{ Grade } \\
\hline Low & 156 & 58 & I & & \\
\hline Medium & 275 & 147 & 1.27 & $(0.86-1.87)$ & \\
\hline High & 442 & 365 & 2.14 & $(1.46-3.14)$ & \\
\hline Not given & 101 & 40 & 1.3 & $(0.78-2.17)$ & $<0.0001$ \\
\hline \multicolumn{6}{|l|}{ Necrosis } \\
\hline Present & 538 & 411 & 1 & & \\
\hline Absent & 72 & 45 & 0.94 & $(0.61-1.46)$ & \\
\hline Not given & 364 & 154 & 0.65 & $(0.49-0.86)$ & 0.006 \\
\hline \multicolumn{6}{|l|}{ Architecture } \\
\hline Comedocarcinoma & 163 & 112 & I & & \\
\hline Mixed types ${ }^{\mathrm{a}}$ & 309 & 278 & 1.46 & $(1.05-2.04)$ & \\
\hline Other specified types ${ }^{b}$ & 326 & 166 & 0.89 & $(0.63-1.26)$ & \\
\hline Type unspecified & 176 & 54 & 0.49 & $(0.32-0.73)$ & $<0.000$ I \\
\hline \multicolumn{6}{|l|}{ Multifocal } \\
\hline No & 737 & 377 & । & & \\
\hline Yes & 237 & 233 & 1.92 & $(1.52-2.43)$ & $<0.0001$ \\
\hline
\end{tabular}

aMixed types: cribriform with solid or papillary architecture or both (64\% of mixed types); comedocarcinoma and other type (I8\%); other (I8\%). ${ }^{b}$ Other specified types: cribriform (4I\%), solid (40\%), micropapillary (13\%) and intracystic papillary carcinoma in situ (6\%).

Other countries have observed increasing incidence of DCIS, sometimes three- to four-fold, with increasing mammographic screening (Ernster et al, 1996; Levi et al, 1997; Zheng et al, 1997; Barchielli et al, 1999; Blanks et al, 2000). This increase has stopped in NSW and we would expect further increases only with growth in BreastScreen participation beyond $53-54 \%$ in $1998-2000$ (Estoesta et al, 2000; Productivity Commission, 2002) or resurgence in mammographic screening reimbursed by Medicare.

We observed a higher proportion of high-grade lesions (54\%) than in Sweden (43\%) and Switzerland (46\%) in the early 1990s, but similar to that, $55 \%$, in an Australia-wide sample survey (Levi et al, 1997; Wärnberg et al, 1999; Shugg et al, 2002). This apparent difference between Australia and these European countries may be real and due to the extent of high-grade disease, or caused by differences in the reporting of grade. It could reflect, too, differences in mammography rates since high-grade DCIS is said to show abnormal mammographic features more frequently than low grade (Evans et al, 2001).

We found that age, high-grade lesions, mixed architecture and multifocality significantly and independently predicted DCIS larger than $2 \mathrm{~cm}$ diameter. That women 20-39 years of age were more likely to have $2+\mathrm{cm}$ diameter DCIS (average $28 \mathrm{~mm}$ in multivariate models in this study) than older women (average $18 \mathrm{~mm}$ ) is probably due to their lower mammography rate. That high-grade lesions were larger probably reflects a correlation with higher growth rate $(1.8 \mathrm{~mm}$ per year low grade, $4.2 \mathrm{~mm}$ 
intermediate and $7.1 \mathrm{~mm}$ high grade; Thomson et al, 2001), particularly since they may also be more readily detectable mammographically (Evans et al, 2001). The Van Nuys prognostic index has shown a parallel increase of size with grade although patients treated with mastectomy, and thus probably the larger lesions, were excluded (Silverstein, 2003). Another series showed a step down from $20 \mathrm{~mm}$ diameter poorly differentiated DCIS to $15 \mathrm{~mm}$ for all other grades (Solin et al, 1991). Our study appears to give the first population-based estimates: the average size increased steadily from $16 \mathrm{~mm}$ for low grade to $20 \mathrm{~mm}$ for intermediate and $27 \mathrm{~mm}$ for high-grade DCIS in the multivariate models of Table 3. Variation in growth rate might also underlie the significant, independent association of architecture with tumour size.

The pathology reports from 1998 to 2000 reported DCIS substantially more completely than did earlier Australian reports (Kricker et al, 1999; Giles et al, 2001; Shugg et al, 2002). The Australian Cancer Network addressed pathology reporting of DCIS with extensive consultation among pathologists in the mid-1990s and published recommendations in 1997 (Australian Cancer Network Working Party, 1997) and 2001 (Australian Cancer

\section{REFERENCES}

Australian Bureau of Statistics (1998) Census of Population and Housing: Socio-Economic Indexes for Areas (SEIFA), Australia. Canberra: Australian Bureau of Statistics

Australian Cancer Network Working Party (1997) The Pathology Reporting of Breast Cancer: A Guide for Pathologists, Surgeons and Radiologists. Sydney: Australian Cancer Network

Australian Cancer Network Working Party (2001) The Pathology Reporting of Breast Cancer: A Guide for Pathologists, Surgeons and Radiologists. Sydney: Australian Cancer Network Working Party

Barchielli A, Paci E, Giorgi D (1999) Recent trends of in situ carcinoma of the breast and mammographic screening in the Florence area, Italy. Cancer Causes Control 10: 313-317

Blanks RG, Moss SM, Patnick J (2000) Results from the UK NHS breast screening programme 1994-1999. J Med Screen 7: 195-198

Choi WS, Parker BA, Pierce JP, Greenberg ER (1996) Regional differences in the incidence and treatment of carcinoma in situ of the breast. Cancer Epidemiol Biomarkers Prev 5: 317-320

Dobson AJ, Kuulasmaa K, Eberle E, Scherer J (1991) Confidence intervals for weighted sums of Poisson parameters. Stat Med 10: 457-462

Ernster VL, Ballard-Barbash R, Barlow WE, Zheng Y, Weaver DL, Cutter G, Yankaskas BC, Rosenberg R, Carney PA, Kerlikowske K, Taplin SH, Urban N, Geller BM (2002) Detection of ductal carcinoma in situ in women undergoing screening mammography. J Natl Cancer Inst 94: $1546-1554$

Ernster VL, Barclay J, Kerlikowske K, Grady D, Henderson C (1996) Incidence of and treatment for ductal carcinoma in situ of the breast. JAMA 275: $913-918$

Estoesta J, Supramaniam R, Brassil A, Taylor R (2000) BreastScreen NSW Ten Year Statistical Report: 1988-98. Sydney: BreastScreen NSW

Evans AJ, Pinder SE, Ellis IO, Wilson ARM (2001) Screen detected ductal carcinoma in situ (DCIS) overdiagnosis or an obligate precursor of invasive disease? J Med Screen 8: 149-151
Network Working Party, 2001). Their adoption by pathologists may explain the more complete reporting we observed.

Increasing incidence of DCIS is an outcome of mammographic screening for breast cancer. The high proportion of high-grade lesions we have observed suggests that its detection could contribute to reducing breast cancer mortality. If it does not, the high frequency of DCIS in association with screening may be source of unnecessary morbidity and cost. More research is needed into the costs and benefits of detection of DCIS in breast cancer screening.

\section{ACKNOWLEDGEMENTS}

The National Breast Cancer Centre, Sydney, Australia funded this study. Incidence data on DCIS in 1995-2000 were supplied by the NSW Central Cancer Registry, which is managed and operated by The Cancer Council NSW under contract to the NSW Health Department.

Giles G, Russell I, Reed R, Marr G, Kavanagh A (2001) In situ and small invasive breast cancer register in Victoria, 1988 to 1992: tumour characteristics and patient management. Aust N Z J Surg 71: $266-270$

Kricker A, Armstrong B, Smith C, Bilous M, Camaris C, Mayer A, Psarianos T (1999) An audit of breast cancer pathology reporting in Australia in 1995. $\mathrm{Br}$ J Cancer 80: 563 - 568

Levi F, Te VC, Randimbison L, La Vecchia C (1997) Trends of in situ carcinoma of the breast in Vaud, Switzerland. Eur J Cancer 33: 903-906

Productivity Commission (2002) Report on Government Services 2002 http://www.pc.gov.au/gsp/2002/

Shugg D, White VM, Kitchen PR, Pruden M, Collins JP, Hill DJ (2002) Surgical management of ductal carcinoma in situ in Australia in 1995. ANZ J Surg 72: $708-715$

Silverstein MJ. (2003) The University of Southern California/Van Nuys prognostic index for suctal carcinoma in situ of the breast. Am J Surg 186: $337-343$

Solin LJ, Recht A, Fourquet A, Kurtz J, Kuske R, McNeese M, McCormick B, Cross MA, Schultz DJ, Bornstein BA, Spitalier J-M, Vilcoq JR, Fowble BL, Harris JR, Goodman RL (1991) Ten-year results of breast-conserving surgery and definitive irradiation for intraductal carcinoma (ductal carcinoma in situ) of the breast. Cancer 68: 2337-2344

Thomson JZ, Evans AJ, Pinder SE, Burrell HC, Wilson ARM, Ellis IO (2001) Growth pattern of ductal carcinoma in situ (DCIS): a retrospective analysis based on mammographic findings. $\mathrm{Br} J$ Cancer 85: $225-227$

Wärnberg F, Bergh J, Holmberg L (1999) Prognosis in women with a carcinoma in situ of the breast: a population-based study in Sweden. Cancer Epidemiol Biomarkers Prev 8: 769-774

Zheng T, Holford TR, Chen Y, Jones BA, Flannery J, Boyle P (1997) Time trend of female breast carcinoma in situ by race and histology in Connecticut, USA. Eur J Cancer 33: 96-100 